\title{
Public engagement in science: Mapping out and understanding the practice of science communication in Latin America
}

\author{
MA DE LOURDES PATIÑO BARBA ${ }^{1}$, JORGE PADILLA GONZÁLEZ \\ DEL CASTILLO ${ }^{1}$ and LUISA MASSARANI ${ }^{2}$
}

\begin{abstract}
${ }^{1}$ Fibonacci - Innovación y Cultura Científica, A.C., Calle Paris 102, Int. 9, Col. Andrade, 37370 Leon, Guanajuato, Mexico ${ }^{2}$ Mestrado em Divulgação da Ciência, Tecnologia e Saúde, Casa de Oswaldo Cruz, Fundação Oswaldo Cruz e Instituto Nacional de Comunicação Pública da Ciência e Tecnologia, Avenida Brasil, 4365, Manguinhos, 21040-900 Rio de Janeiro, RJ, Brazil

Manuscript received on December 13, 2017; accepted for publication on April 30, 2018
\end{abstract}

How to cite: BARBA MLP, DEL CASTILLO JPG AND MASSARANI L. 2019. Public engagement in science: Mapping out and understanding the practice of science communication in Latin America. An Acad Bras Cienc 91: e20171000. DOI 10.1590/0001-3765201920171000.

\begin{abstract}
This article presents the results of a study aiming to map out the characteristics of science communication activities carried out in Latin America by different organizations. We looked at a general description of the activities (such as the kind of activities carried out, in which periodicity, the publics engaged in the activities, etc.) and the favorable and unfavorable existing conditions in the organizations (such as budget and planning, evaluation, as well as weakness and strengths). The study focused on gathering primary information, through an online survey, answered by 123 institutions from 14 countries. Although the results are not representative of the entire Latin America - and it would be not possible to be so, since it is not even known the totality of initiatives existing in the region -, the study presents trends that can help the guidance and the consolidation of strategies for strengthening the practice of science communication in the region.
\end{abstract}

Key words: Latin America, science and public, science communication, science popularization.

\section{INTRODUCTION}

\section{BACKGROUND}

Provided the lack of diagnostic and analytical data on science communication at regional level ${ }^{1}$, studies have recently been undertaken to deliver

\footnotetext{
${ }^{1}$ Mexico is the country in which several studies have been carried out for mapping science communication (see, for example, Herrera et al. 2006, Patiño et al. 2013a, b.
}

Correspondence to: Luisa Massarani E-mail: luisa.massarani@fiocruz.br / luisa.massarani6@gmail.com ORCid: http://orcid.org/0000-0002-5710-7242 relevant information in Latin American countries, to guide and strengthen institutional efforts of communicating science.

This article is part of this set of studies. There are records of science communication activities in several Latin American countries for at least the past two centuries (see, for instance, Moreira and Massarani 2002, Massarani and Moreira 2015, Sánchez-Mora et al. 2015, Fog 2004). However, it was in 1960 s that an innovative educational movement, rooted in the importance of experimentation for science education, began in several Latin American countries, following the 
influence of some changes, mainly in the United States (Massarani et al. 2015a). In addition to improve formal science education, this movement sought to increase the level of the scientific culture of the population using different media, spaces, strategies and products to communicate science.

Although the movement was broader, we will comment specifically two fields of science communication that had particular momentum at that time. ${ }^{2}$ The first of them is science journalism, subject of widespread enthusiasm in some of the countries in the region (Massarani et al. 2012, Cazaux 2010). Several conferences and other actions involving Latin Americans and Spaniards took place, which led to the creation of the IberoAmerican Association of Science Journalism in 1969. National associations in Argentina (1969), Venezuela (1971), Chile (1976), Colombia (1976) and Brazil (1977) were also created and several regional newspapers intensified their science sections at that time.

The other field that deserves to be highlighted in this period of time are the hands-on science museums/centers. Whereas natural history museums date back to the $19^{\text {th }}$ century, the first hands on science museums were created in the region only in the 1970s, including, just to mention some: Museo Tecnológico (1970, Ciudad de México, Mexico), Centro Cultural Alfa (1978, Monterrey, Mexico), Centro de Divulgação Científica e Cultural, associated to the University of São Paulo (1980, São Carlos, Brazil), Espaço Ciência Viva (1982, Rio de Janeiro, Brazil), Museo de la Ciencia y el Juego (1984, Bogotá, Colombia), Museu de Astronomia e Ciências Afins (1985, Rio de Janeiro, Brazil), Estação Ciência (1987, São Paulo, Brazil), Museo Participativo de Ciencias (1988, Buenos Aires, Argentina) (Massarani et al. 2015). During the 1990s and 2000s, many Latin American countries created other hands on

${ }^{2}$ For further information, see Massarani (2015). science museums/centers. In 2015, the Network for Popularization of Science and Technology in Latin America and the Caribbean (Red de Popularización de la Ciencia y Tecnología en América Latina y el Caribe, RedPOP) published a guide of science centers and museums in Latin America and the Caribbean (Guía de Centros y Museos de Ciencia de América Latina y el Caribe) (Massarani et al. 2015b), which shows how the area developed: 470 organizations were identified in different Latin American countries.

The creation of RedPOP itself highlights how the actions developed for the science communication in Latin America have been intensified (Massarani 2015). This network, composed of groups, programs and centers engaged in science communication in Latin America and the Caribbean, was created in November 1990, in a movement in the scope of the Regional Science Office of the United Nations Educational, Scientific and Cultural Organization (UNESCO) for Latin America and the Caribbean. It was launched in a meeting held at the newly created Museu de Astronomia e Ciências Afins, in Rio de Janeiro.

Approximately 20 organizations from Argentina, Brazil, Costa Rica, Colombia, Cuba, Guatemala, Mexico and Venezuela participated in this meeting. Currently, the network has approximately 80 members; and 400 to 500 people participate in its biennial conferences.

The academic field of science communication, however, is more recent. According to Massarani et al. (2017), systematic academic production began in the 1980s and more than 600 academic articles have been published in the region so far. Postgraduate programs were only created in the 1990s. Twenty-two programs have been identified in five regional countries, $65.0 \%$ of which date from the past 10 years (Massarani et al. 2016). 
INSTITUTIONS PERFORMING IN SCIENCE COMMUNICATION IN LATIN AMERICA

Institutional as well as individual social actors have made efforts to communicate science to Latin American populations.

The set of identifiable actors working in science communication in the region comprises a variety of institutions and groups (and even individual communicators who work independently), including:

- Universities and higher educational institutions, in which there are programs and actions in science communication;

- Institutes and research centers that, in addition to research and training of highlevel human capital, carry out science communication actions;

- Public or Government dependent bodies, including governing bodies in the sector of science and technology - that communicate science as part of their basic functions, in their disciplinary fields of action (health, environment, etc.).

Among the associations of science communicators, the following are noteworthy: the abovementioned Red de Popularización de la Ciencia y la Tecnología en América Latina y el Caribe, (RedPOP), the Mexican Society for the Science and Technology Communication (Sociedad Mexicana para la Divulgación de la Ciencia y la Técnica, SOMEDICYT), several Mexican state science communicator networks, the Brazilian Association of Science Centers and Museums (Associação Brasileira de Centros e Museus de Ciência, ABCMC), the Mexican Association of Science and Technology Museums and Centers (Asociación Mexicana de Museos y Centros de Cienciay Tecnología,AMMCCYT), the Argentinian Association of Science and Technology Centers and Museums (Asociación Argentina de Centros y Museos de Ciencia y Tecnología, AACMC), the Chilean Association of Science Journalists (Asociación Chilena de Periodistas Científicos, ACHIPEC), the Science Journalism Circle of Venezuela (Círculo de Periodismo Científico de Venezuela, CPCV), the Colombian Association of Science Journalism (Asociación Colombiana de Periodismo Científico, Colombia), the Argentinian Network of Science Journalists (Red Argentina de Periodistas Científicos, RADPC), the Mexican Network of Science Journalists (Red Mexicana de Periodistas de Ciencia, RedMPC), Liliput - Network of small interactive museums in the Andean area of Colombia (Red de pequeños museos interactivos del área Andina de Colombia), the IberianAmerican Network for Science Communication (Red Iberoamericana de Comunicación y Divulgación Científica, OEI), the IberianAmerican Network for Science Communication and Culture (Red Iberoamericana de Divulgación y Cultura Científica), and the Community of Iberian-American Educators by Science Culture (Comunidad de Educadores Iberoamericanos por la Cultura Científica, CECC).

\section{POLICIES FOR SCIENCE COMMUNICATION}

In Latin America, the agendas of national bodies for science and technology (Organismos Nacionales de Ciencia y Tecnología, ONCYTs) have sometimes included the promotion of scientific culture, with a somewhat boosted priority on selected occasions: in 2016, 14 Regional countries had policies or actions to promote scientific culture (Fernández et al. 2016).

However, public policy strategies for public science communication are very different from country to country in the region. This is due to a set of variables such as the different degree of development of the Science, Technology \& Innovation (ST\&I) systems and differences in the organizational structure control. The countries with the largest number of activities in science 
communication, also making the major investment on research and development as a percentage of their GDP, are Argentina, Brazil, Chile and Mexico (Fernández et al. 2016).

The implementation of public policies, specific legislations and legal instruments for the promotion of scientific culture could be the opportunity to begin a process of reorienting the ST\&I systems so that, at mid-term, regarding scientific promotion and education, they could reach a development level similar to the one they have reached regarding research and development (R\&D), innovation and technology transfer.

Despite some progress, specific public policies and legal frameworks for the communication of science, or other strategies for strengthening scientific culture, are still fragmentary or somewhat incipient. Furthermore, as it is generally so concerning policies in Latin America, there is some instability and lack of continuity, regarding policies and strategies for scientific culture.

Several countries have developed "best practice" models for policies in the field, which facilitate the communication that strengthens scientific culture. However, further development of science journalism and of the use of Internet resources is still needed, such as the use of social networks. Besides, strengthening and improving science teaching in the educational system have been highlighted as key factors for the construction of the scientific culture in several countries (Mexico and Uruguay, among others).

This article presents the results of a study aiming to map out the characteristics of the science communication activities carried out in Latin America by different organizations. The aims of this study were the following:

- Identify the modalities of science communication developed in Latin America and, to the greatest possible extent, size them quantitatively;
- Identify and characterize the public segments that are engaged in science communication in Latin American countries;

- Identify the favorable and unfavorable existing conditions in the Latin America countries, with respect to science communication.

\section{MATERIALS AND METHODS}

This study was designed and conducted by Fibonacci - Innovación y Cultura Científica, A.C. (Leon, Mexico) and the abovementioned RedPOP. ${ }^{3}$

Information was gathered for three months (March to May 2016), by means of an online survey, addressed to the diverse actors that run programs and carry out science communication actions in Latin America.

A full quantitative description of all the institutions playing in the regional science communication field would have demanded massive effort and time investments, besides the fact that it is unknown the total universe in this field. Therefore, it was decided that the call for the survey would be broadcasted through the existing RedPOP databases, web pages, newsletters, direct invitations and by snowball sampling (nonprobability sampling technique, where existing study subjects recruit future subjects from among their acquaintances).

\section{THE SURVEY}

The information was gathered from an online survey, designed according to the objectives of the project. The questionnaire integrated 20 closedended questions and 22 open-ended questions. The first part of the survey asked for institutional data from respondents, which allowed classifying them. The second part comprised the questions related to

${ }^{3}$ For further information on the study and its results, see Patiño et al. 2017. 
the purpose of the survey, expressed in accordance with the information that was searched.

The information desired was the following:

- Modalities and types of scientific communication activities carried out by each institution (grouped by mass media, publications and other editorials, Internet, programs and events, production of audiovisual and teaching material, visits to venues such as science centers and museums, zoos, etc.);

- Average audience attended yearly by the science communication actions and programs;

- Average proportions of people engaged per year, in different segments (children, teens and adult, students, general public, urban, rural);

- Human, organizational, technical and financial resources available to the institutions for science communicate activities (dedicated organizational units, annual budget, work plan, internal and external personnel, volunteers / impact records / cultural impact assessment systems / material resources);

- Favorable (opportunities) and unfavorable (limitations) aspects of the environment to carry out the science communication;

- Internal/institutional strengths and weaknesses for an effective work of science communication.

Once validated, the questionnaire was entered in the online system (SurveyMonkey) in Spanish and Portuguese, and the call was launched. The quantitative results were statistically processed and the qualitative results were organized by the $\mathrm{KJ}$ (affinity groups) technique to facilitate the analysis. The obtained products were a characterization of the science communication of the Latin American institutions that responded to the survey and a SWOT analysis (Strengths and Weaknesses of the science communication carried out in the region, and Opportunities and Threats from the environment). ${ }^{4}$

Finally, based on the information obtained from the survey and other information about the context from secondary sources, the relevant diagnostic conclusions were formulated.

\section{SAMPLE AND REACH}

As far as we know, there is not an exhaustive inventory of the institutions and groups that perform science communication actions in Latin America. In other words, the total universe of the organizations carrying out science communication activities is unknown. For reference purposes, a guide of science museums/centers in Latin America and the Caribbean gathers information from approximately 470 organizations (Massarani et al. 2015b). As already mentioned, museums and centers are only some of the organizations involved in science communication.

Therefore, the results reported in our article are not representative of all institutions and groups that implement science communication actions in the region. The results show a "characterization" of the corpus created by those that responded to the call and filled out the survey. On the other hand, our results present some trends concerning science communication in the region. Furthermore, as no previous exhaustive inventory of science communication organizations was consolidated in the region, this study is an important tool for start filling this gap.

The survey was conducted in Spanish and Portuguese. Therefore, it was potentially intended to the 20 countries where these languages are spoken (Argentina, Bolivia, Brazil, Chile, Colombia, Costa Rica, Cuba, Ecuador, El Salvador, Guatemala, Honduras, Mexico, Nicaragua, Panama, Paraguay,

\footnotetext{
${ }^{4}$ The results of the SWOT analysis will not be discussed herein, since there is a lack of space, but rather in a further publication.
} 
Peru, Dominican Republic, Puerto Rico, Uruguay and Venezuela).

Altogether, 123 answers from institutions and groups (not all members of RedPOP) were received from 14 countries (Argentina, Bolivia, Brazil, Chile, Colombia, Costa Rica, Cuba, El Salvador, Mexico, Nicaragua, Paraguay, Peru, Uruguay and Venezuela).

Although it was desirable that other countries in the Caribbean answer the survey, it is important to mention that there are few groups and institutions working within science communication on the islands. In addition, almost all islands have languages different from Spanish and Portuguese, which were the languages used for the survey, there was a significant language barrier for the Caribbean to participate in the study.

\section{RESULTS AND DISCUSSION ${ }^{5}$}

The greatest number of surveys $(77.0 \%)$ came from Mexico, Brazil and Argentina.

The institutions that answered the questionnaire classified themselves in several categories (Figure $2)$, the main ones are: institutions of higher education $(28.0 \%)$, hands on science centers and museums $(18.0 \%)$, associations or groups of science communicators $(12.0 \%)$. The category "others" encompasses foundations, astronomical observatories, schools (of elementary, medium and high-school levels), scientific associations and programs. Seventy one percent of the 123 answers were received from public institutions, the others from private ones.

In the questionnaire, we asked the institutions since when they were carrying out science communication activities. The results showed a wide range of answers, although science communication actions were mostly launched during the past four

\footnotetext{
${ }^{5}$ The data reported by the organizations answering the survey date from 2015, that year being the last completed one before the survey took place.
}

decades. As it can be seen, it seems that there was a boom regarding communication activities performed by new and pre-existing groups and institutions, starting in the 1980 s, reaching its the highest peak in the years 2000 . The average time amount during which the surveyed institutions have communicated science is 18 years, ranging from less than a year to 109 years.

\section{TYPES OF SCIENCE COMMUNICATION ACTIVITIES}

The questionnaire enlisted a wide range of strategies, modalities, means and specific activities in science communication, in order that the representatives of the surveyed organizations could indicate the ones they were using. An option to add other activities not previously indicated was also included.

The most-frequently used strategies to communicate science are: events and programs (99.2\%), Internet (94.3\%) and publishing/editorial products $(82.1 \%)$. When the total amount of actions by scientific institutions and organizations that answered the survey are gathered and split by type, the resulting proportions are as shown in Figure 1.

The strategies and means used for communicating science are diverse, being science communication events and programs ${ }^{6}$ the most widely used ones, followed by Internet (a growing strategy) and mass media (amounting 12.8\% of the total activities).

Figure 2 shows how often communication activities take place. There is evidence that the frequency under which many communication actions are carried out in Latin America is very low or equal to zero (frequencies tagged "Casual or occasional" or "None", reached $68.3 \%$ ).

The periodicities prevailing for communicating science are eventual or occasional (14.9\%), annual

\footnotetext{
${ }^{6}$ Conferences, lectures, workshops, courses, fairs, shows of prototypes, travelling exhibitions, competitions, science clubs, experimental shows, tours, astronomical observations, summer courses, roundtables, etc.
} 


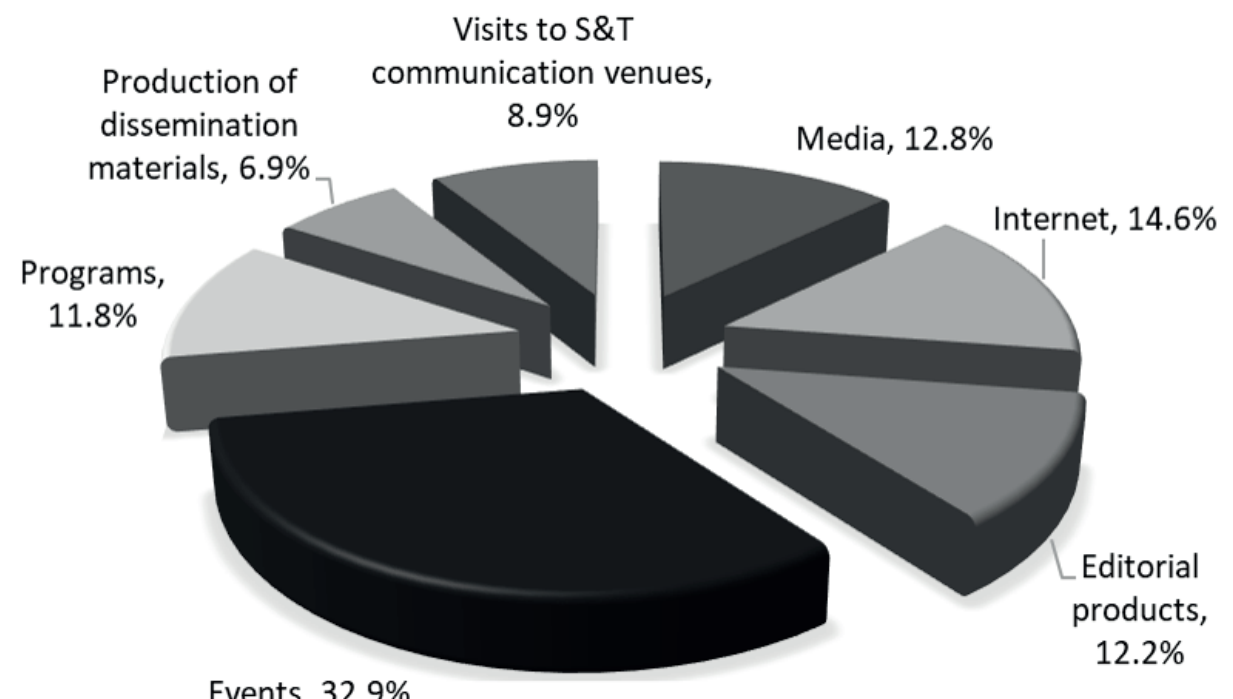

Figure 1 - Proportion of types of science communication actions employed by the set of institutions that answered the survey. Source: designed by authors.

$$
\text { Daily Weekly } \square \text { Monthly } \square \text { Quarterly } \square \text { Biyearly } \square \text { Yearly } \square \text { Ocassional } \square \text { None }
$$

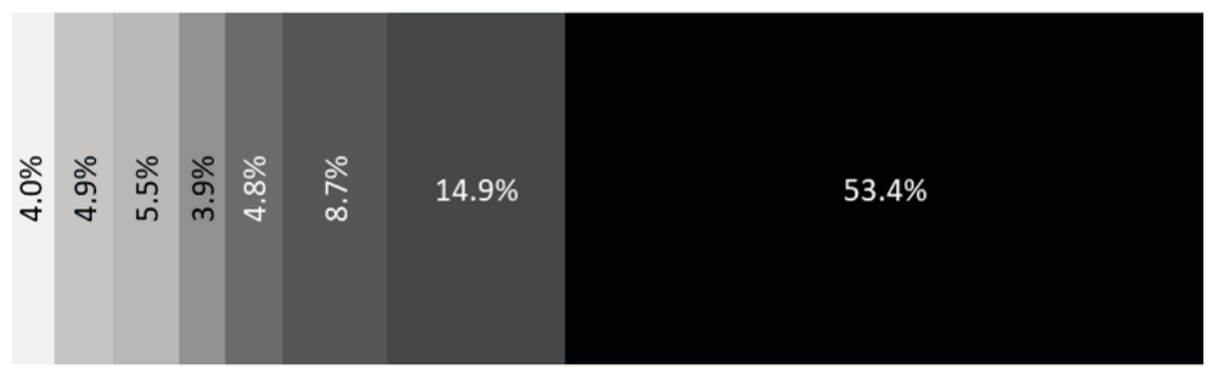

Figure 2 - Frequency of science communication actions carried out by the set of institutions that answered the survey. Source: designed by authors.

$(8.7 \%)$, once a month $(5.5 \%)$. That is to say that, generally, the undertaken actions are intermittent, which limits the ability to impact the different audiences in different ways.

Thus, science communication activities are diverse in Latin America, at least regarding the organizations that participated in this study. However, institutions do not usually undertake such actions steadily. Activities carried out on daily, weekly and monthly basis represent only $14.3 \%$ of the total. A few specific communication activities are carried out daily, they are mainly information published on websites, Facebook and Twitter. Some scientific institutions also hold daily science workshops, exhibitions, video projection, science demonstrations and visits of facilities.

\section{THE PUBLIC}

Only one institution did not provide information about the public segments they were serving according to age. As to the other 122 surveyed institutions. 
About one third of the public engaged in science, according to the survey, comprises children under 12 years old, whereas nearly $43.0 \%$ are teenagers, between 13 to 18 years old.

According to the UN world population report (UN 2015), the population distribution by age in Latin America is as follows: children (0 to 9 years old), $18.5 \%$; pre-teen (10-14 years old), $8.8 \%$; teenagers (15-19 years old), $8.8 \%$; adults (20 years old and + ), $65.5 \%$. Even if the age categories in the survey do not correspond to the UN report's categories, a special attention is apparently given to children up to 12 years old, representing $28.9 \%$ of the attended population whereas children in the UN report (under 9) represent $18.5 \%$ of the general population. The same trend is observed in the teenagers' segment in a more pronounced way, since they represent $42.9 \%$ of the attended population, whereas in the UN report, young people between 10 to 19 years old are $17.6 \%$ of the general population. The Latin American adult population (older than 19 years-old) is clearly under-attended by the set of institutions that answered our survey. Despite the fact that adults represent $65.0 \%$ of the general regional population, only $28.2 \%$ of the activities are target to them. By drawing attention to these proportions, it is not our intention to minimize the huge importance of engaging children and young people in science. To achieve an appropriation of science and technology by the entire society, appropriation of S\&T by the entire population of the countries.

As to the type of audience served depending on their location (urban or rural), the proportions are similar to that of the total population of the region, according to the United Nations Division of Population in Latin America and the Caribbean (ONU 2014). The urban population represents $79.5 \%$ of the total regional population, being the rural one only $20.5 \%$. The survey shows that the institutions, through their programs and activities for the communication of science, attend $77.6 \%$ of the urban population and $22.4 \%$ of the rural one. Therefore, they serve the inhabitants of rural areas at a degree slightly higher than the percentage of this population considering the total population of the region.

Vulnerable populations include a heterogeneous group of population segments that are in a deficiency or disadvantage situation, as compared to other members of the community. This can be due to various socio-economic and/or cultural conditions: people with low income, rural population, indigenous people, the elders, etc. In the survey, it was inquired if institutions targeted in general vulnerable populations through their actions. Surveyed institutions do serve vulnerable populations with some prominence, since $69.1 \%$ of 123 institutions have at least one program or one action aimed at this segment. However, only 69 of the 123 specified the types of vulnerable populations they were serving through actions of science communication. Some of them focused on more than one type of vulnerable population.

Communication is higher towards people with disabilities (45 institutions), groups living in poverty (27 institutions), rural communities (11) and indigenous communities (10).

There was also a specific question about the activities directed to people with disabilities, since several organizations of science communication in the region have called attention to the need of a more inclusive approach towards this segment of society. The response was that almost $37.0 \%$ of the institutions have a program focused on disabled people, being the ones with visual and mobility disabilities the most attended ones, with $13.6 \%$ and $7.3 \%$ of the actions, respectively.

\section{INSTITUTIONAL RESOURCES}

Only $65.9 \%$ of the surveyed institutions have a functional unit (Department, Center, etc.) in their organizational structure responsible for 
communicating science (not necessarily for communicate science; in some cases, it might do so together with other functions, such as networking and institutional communication) and have staff specifically assigned to carry out for science communication activities.

In addition, only $49.6 \%$ of the surveyed institutions have specific budget for science communication activities and programs. The budget differences among the various institutions are very large: from USD 50 up to USD 6,688,000 per year.

Figure 3 shows the range of budgets (in USD) in the subset of institutions that reported having a specific budget for science communication and provided their data. Thirty point four percent of them have less than USD 10,000/year whereas $42.9 \%$ have less than USD 20,000/year (Figure 3).

From the subset of institutions that reported having a specific annual budget for science communication, $83.6 \%$ of them also reported the proportion representing that assigned amount in the general institution's budget. According to the results, $58.8 \%$ of those institutions dedicate $10.0 \%$ or less of their total budget to public science communication whereas in $11.8 \%$ of the cases, $100 \%$ of the budget was target for such purpose.

The important proportion of institutions that reported zero or low budgets allocated to the science communication of science may be due to various factors, which include, undoubtedly, institutional shortcomings or resource constraints. However, this may also be so due to the fact that science communication is not the primary function of many institutions, for instance, as happens in higher education institutions and research centers. In other cases, such as science communication magazines, the percentage of the overall budget dedicated to the science communication is naturally high.

Another institutional resource for practice of science communicating consists in formulating annual plans for the programs and actions in this field. A formal plan allows the institution to organize the set of actions on a solid basis and with focus, with a forecast of the needed human and financial resources and with an established schedule. In the most successful cases, annual plans tend to be part of or be consistent with broader institutional plans.

However, the data show that $28.5 \%$ of the surveyed institutions does not have a formalized annual science communication plan. This may indicate either the realization of actions guided by inertia or depending on chance or opportunities, or a set of actions actually focused, planned and developed on solid foundations, but without any formalization.

A very important resource for any professional activity is human capital. Therefore, in the Latin American survey, a specific section was dedicated to investigating who carries out science communication activities. It is remarkable that slightly more than $60.0 \%$ of the human resources of the surveyed institutions carries out those activities for free; almost $92.0 \%$ of institutions have volunteers as part of their human resources, at least. On the one hand, this reveals people's willingness to work without any income, but, on the other hand, it makes the institutions heavily dependent on attracting that kind of people (which, in addition, could be more "volatile" in terms of keeping the job than the paid ones). Thus, just $8.1 \%$ of the institutions pay their whole staff for their communication activities. This value may indicate low professionalism from those who are involved in the practice of science communication in the region. In the same direction, Figure 4 reveals that only $10.1 \%$ of the institutional staff consists of professional science communicators.

It is interesting to observe that researchers represent about one third of the human resources that perform science communication actions, according to the survey. Students under contract or receiving grant occupy the second position (18.6\%), followed by technical staff (18.2\%). The "Others" 


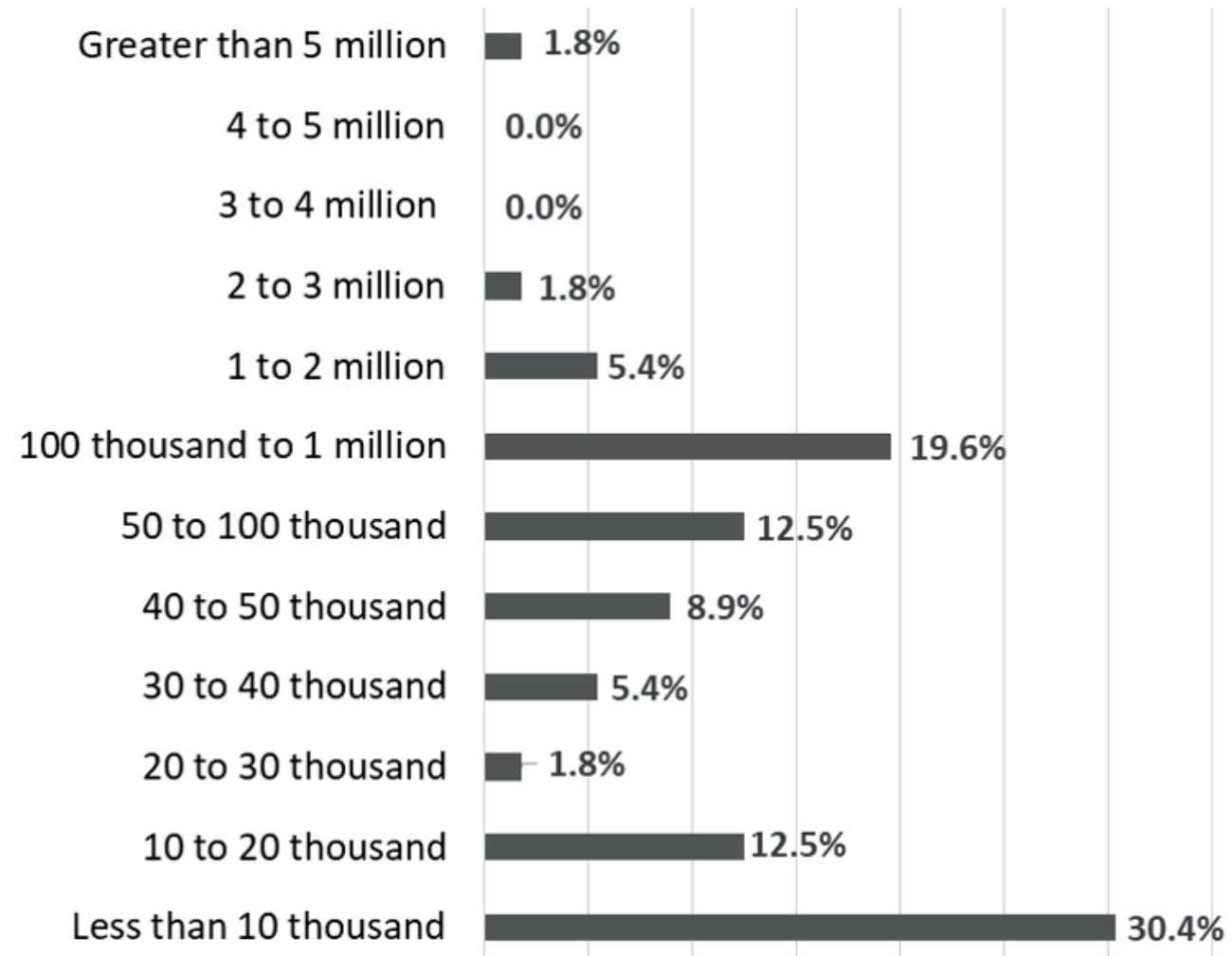

Figure 3 - Range of annual budget dedicated to science communication programs/activities in institutions that reported having one (US dollars). Source: designed by authors.

category $(8.6 \%$ of the total) includes designers, volunteer staff, students and alumni who perform social services, fund managers, institutional communicators and even administrative staff.

It is important to note that the authors of this paper value the science communication activity carried out by all different social actors. In this sense, two examples are given here: we consider crucial that researchers interact directly with the society, as part of the consolidation of a social pact between science and society. It is also essential that students from different knowledge areas of knowledge be involved in science communication activities, while they consolidate bases to become well-trained citizens in the scientific culture (whatever career they might follow). However, what is highlighted herein is the need for a professionalization of the science communication field, since, as abovementioned, only $10.1 \%$ of staff undertaking science communication activities are professionals - a percentage excessively low.

Another variable refers to the time dedicated by the staff to the activities of science communication. According to the results of the survey, $7.7 \%$ of the staff is half time workers, whereas more than half $(56.7 \%)$ is less than half-time workers on science communication activities. Only $35.6 \%$ of the staff dedicated to science communication makes it on a full-time basis. For purposes of comparison, $69.0 \%$ of 275 science journalists, from 16 Latin American countries said they had a full-time job (12.0\% of them work as independent professionals (Massarani et al. 2012)).

With regard to the gender of staff dedicated to the science communication in the region, there are slightly more women (almost 53.7\%) than men, according to the data obtained from the surveyed institutions. 


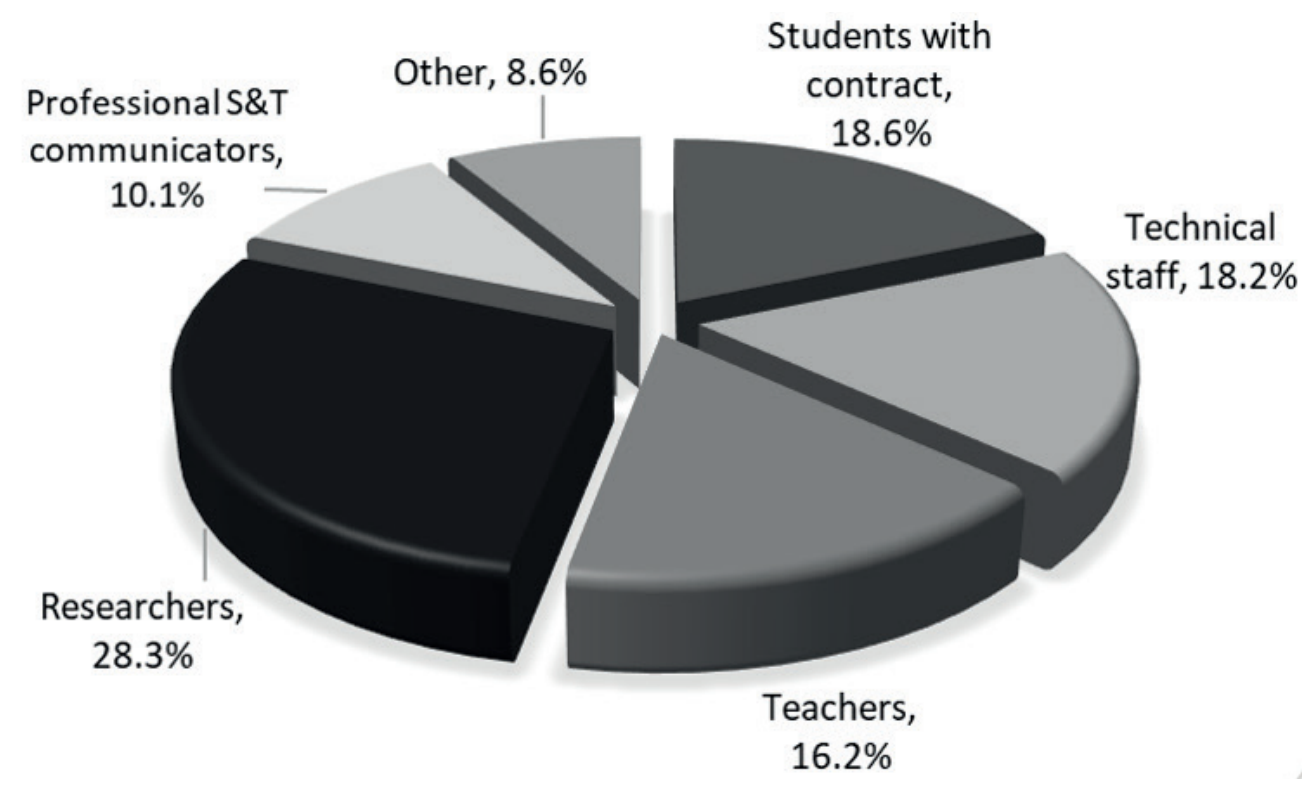

Figure 4 - Main occupation of staff carrying out activities for the communication of science. Source: designed by authors.

According to the United Nations data for 2015, women are about $50.6 \%$ and men $49.4 \%$ of the population in Latin America and the Caribbean (ONU 2015). Regarding the percentage of women in science, UNESCO consultant Alejandro Bello reported to SciDev.Net, in 2014, that Latin America has the highest proportion in the world (about $45.0 \%$ ) of female researchers, much higher than in developed countries (Amorim 2014). The average rate of female scientists in the whole world is $25.0 \%$. These data are merely referential, because - of course - not all scientific activities are science communication and not all science communicators are scientists. Another reference is the abovementioned research conducted among Latin American science journalists: $59.0 \%$ of 275 journalists from 16 Latin American countries who answered a survey were women (Massarani et al. 2012).

Finally, the survey asked about external personnel used by the institutions to support their science communication activities. The external personnel who mostly collaborate with institutions in science communication activities are: academic scientists and researchers from other institutions (31.4\% of the total), volunteers ${ }^{7}(28.8 \%)$ and scholarships holders and students in social service $(27.7 \%)$. The group of external communicators is only $4.0 \%$ of the total. The collaboration of professionals and specialists from companies is also scarce.

\section{RECORD AND EVALUATION OF ACTIVITIES}

An impact analysis of science communication actions in the region requires to record, measure, analyse and evaluate the number of people engaged in these actions, as well to evaluate the change generated in the public by the science communication activities, projects and programs. Therefore, some registration and evaluation-related questions were included in the survey. The results are detailed below.

\footnotetext{
7 "Volunteer" means: teachers or professionals in various areas who carry out the science communication activities by vocation or willingness to collaborate without being paid.
} 
Out of the institutions that responded to the survey, $32.5 \%$ do not keep any record of the public engaged nor of their science communication activities. ${ }^{8}$ This obviously limits substantially any attempt of sizing and evaluating the impact of the science communication actions they perform.

Of the subset of institutions that record their attendees and impact (two-thirds of the total), $42.9 \%$ record only their quantitative impact, $53.6 \%$ keep both quantitative and qualitative records and $3.6 \%$ record qualitative impact only.

Only $34.1 \%$ of institutions have systems to evaluate their science communication activities; $44.4 \%$ of this subset of institutions works with performance indicator systems, another $44.0 \%$ with evaluation programs ${ }^{9}$ and $11.1 \%$ works with both types of systems.

These results confirm Fernández et al. (2016), who point out that there are not enough evaluations and impact analysis of the instruments and activities to strengthen scientific culture, that there is a lack of indicators for monitoring and managing the activities that are financed and that the methodologies for evaluating science communication activities are not yet adjusted.

\section{SELECTION OF S\&T TOPICS BY THE INSTITUTIONS}

In the survey, the surveyed Latin American institutions were asked to indicate how they made their choices, regarding the subjects to be

\footnotetext{
${ }^{8}$ This situation was also evidenced during the survey process, when several people, commissioned by their institutions to answer the questionnaire, claimed not having complete and structured records that could provide reasonable statistics.

${ }^{9}$ Indeed, a comprehensive system of evaluation may include indicators, among other methods; but here we differentiated evaluation systems based solely on performance indicators from those that involve qualitative assessments (interviews, focus groups, observation, etc.) including statistical processing (such as surveys) that do not necessarily generate indicators and indexes.
}

treated during their communication activities and programs. The responses are shown in Figure 5.

Out of the scientific topics that are reported in Latin America, mostly are defined by communicators themselves, according to their disciplinary fields and professional training or work; they are marginally chosen from the detection of the needs and interests of targeted audiences. In these choices, consistency with the preferential lines, as defined by the institutional authorities, is not a predominating criterion.

This fact is not groundless, because it is difficult for a researcher, an academic teacher or a science communicator to report issues that are not part of his/her own field of work or interest. This is emphasized, because, as other results of the survey have shown, the majority of these professionals work without being paid. Ideally, the thematic definition of the science communication actions should be established based on the needs and interests of the public, or agreed upon with them, to ensure a full social relevance of the science communication.

\section{GENERAL CONSIDERATIONS}

The institutions in this study reported that they used a variety of strategies and means for science communication; events and programs (such as conferences, workshops, exhibitions and prototypes, science fairs, etc.) are largely predominant. A great number of institutions in the region uses this strategy.

Science communication has increased consistently through digital media and Internet; technological development has provided new resources to science communicators. A very high proportion (94.3\%) of Latin American institutions that responded to the survey reported science communication activities through the Internet: the most commonly used modalities are social networks (with a predominance of Facebook) and 


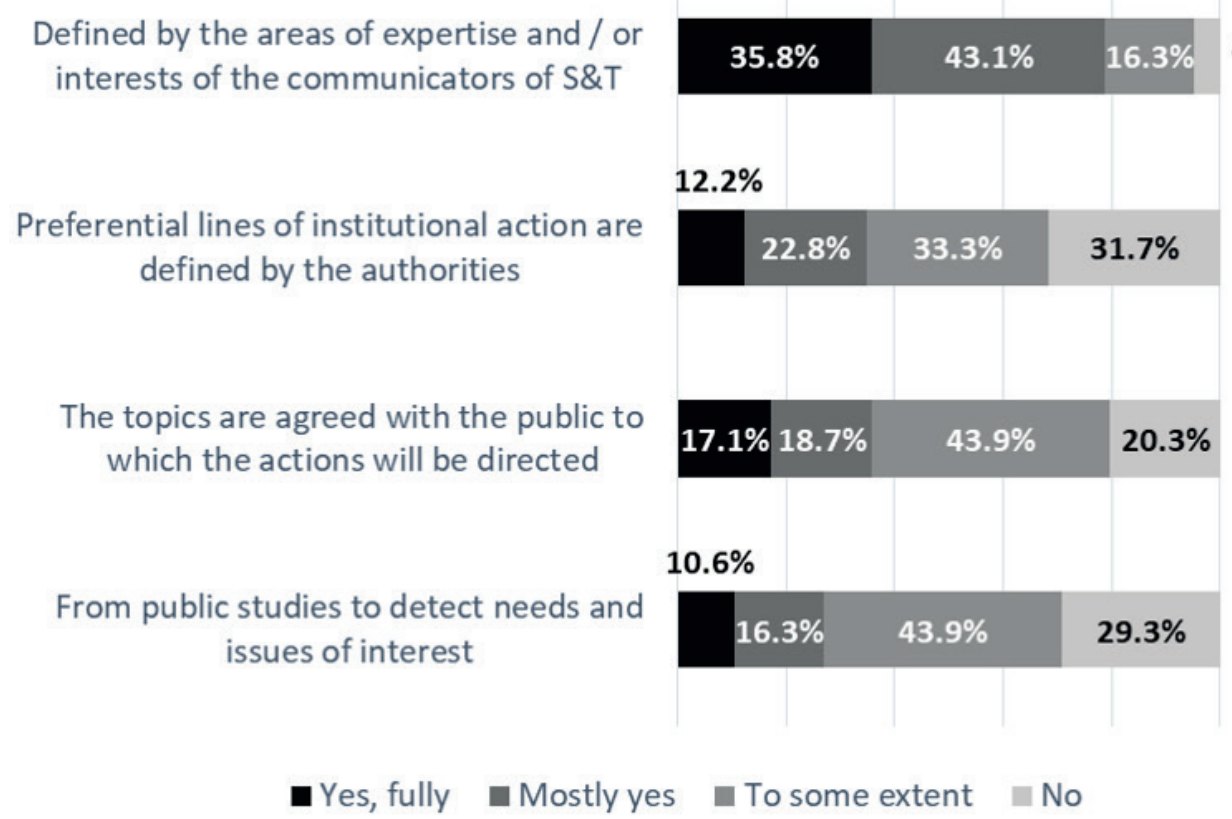

Figure 5 - Basic choice criteria used to determine S\&T themes. Source: designed by authors.

the institutional portal or science communication websites.

However, although the surveyed institutions use a variety of strategies to communicate science, more than half of the actions are carried out occasionally or without any periodicity. This lack of periodicity limits the ability to reach different audiences, in different ways, in a sustained manner and it negatively impacts science communication outcomes.

The results obtained from the survey show that the main audience for science communication in the region is aged between 13 to 18 years old. Almost two-thirds of the actions focus on the educational (students and teachers) sector. In general, such audience is better defined by the communicators and more accessible than other society sectors. Without reducing the importance of involving young people in science communication, it is relevant to mention that the adult audience can be considered as underattended in the surveyed institutions.

In general, the proportions of science communication actions aimed at rural and urban inhabitants are in accordance with the population structure of the Latin American region as a whole.

Besides, in general, the surveyed institutions have tendency to assist different populations in conditions of vulnerability, since $69.1 \%$ of them have at least one program or action aimed at these population segments. Most institutions serve people with disabilities, poverty groups, rural and indigenous communities. The proportion of actions addressed to people with disabilities is still reduced though.

The organizations reported that their own communicators were the ones who defined most of the S\&T topics that are dealt with (depending on their disciplinary and professional areas, training or work fields, which is plausible and logical). It is questionable, in the results, that the choices of topics are not chosen according to the positions defined by the institutions' authorities.

Topics are only minimally defined based on the detection of the needs and interests of the public to which they will be directed. This could point to a poor institutional focus on what the science 
communication recipients require, or to the lack of public studies and field research on citizens' scientific culture.

Another important result that stood out from this study was a clear set of limitations in the organizational structures and resources for science communication.

The survey showed that in general, Latin American institutions that perform science communication suffer some structural, organizational and resource weaknesses to carry out their tasks:

- A little more than one-third of the institutions do not have an organizational unit (department, center, direction, etc.) directly responsible for science communication activities, or having specific functions in this field;

- Almost half of the institutions do not assign a formal and specific budget for science communication actions;

- About $30.0 \%$ of the institutions do not have a formal annual plan for their science communication activities.

Regarding professional versus volunteering workforce, it is remarkable that just over $60.2 \%$ of the surveyed institutions only have staff that carries out science communication activities for free and $91.9 \%$ partly uses volunteer staff. On the one hand, this reveals people's willingness to work without income in return; on the other hand, it makes institutions heavily dependent on attracting that kind of people (which could be more "unstable" than paid employees).

Thus, in only $8.1 \%$ of the institutions are science communication actions exclusively carried out by paid staff. Looking at human resources, this result may be indicative of a low level of professionalism for science communication in the region and of a high dependency on personnel who work either freely or voluntarily. In addition, only $10.1 \%$ of the communicators are professionals.
Researchers (who represent $28.3 \%$ of the total) are the main group in charge of the science communication actions, followed by the group of contracted students.

The majority of those who perform science communication actions in the institutions from this study do so on a part-time basis, because they also have other functions and duties. Only $35.6 \%$ of the staff works on a full-time basis. In the surveyed institutions, external professional communicators and specialists from other companies are scarcely casted.

Another result of the study that draws attention is the little documentation, registration and evaluation of impact that the organizations undertake. A little more than one-third of the institutions that responded to the survey do not perform any kind of record of the public attended by science communication actions. ${ }^{10}$ In the subset of institutions that keeps records, a little more than half of them have both quantitative and qualitative records. Only a third of the institutions have evaluation systems of their science communication activities and impacts.

\section{RECOMMENDATIONS}

- Institutions surveyed in this study reported to use a diversity of strategies and means for communicating science. However, to increase the chances of impact of the actions carried out on the population's scientific culture and appropriation of S\&T, it is necessary to increase the frequency

\footnotetext{
${ }^{10}$ Beyond the direct responses given by institutions to the questions corresponding to this topic, lack of records and statistics could explain the lack of answer to the survey from some institutions, i.e. when they had to face questions demanding specific data. Some institutions expressed that they had difficulties to get information that would allow them to complete the questionnaire, particularly concerning the public assisted by activities.
} 
and continuity of science communication actions at the institutional level.

- Internet and electronic media are important ways of communicating S\&T nowadays. Although the use of these resources is already broad in science communication activities, it is convenient to use them even more and more frequently, since they involve relatively low costs and have potential to reach remote audiences, which would otherwise probably be unreachable. It should be borne in mind that certain population segments would not be served by this type of media for various reasons, i.e. digital illiteracy, poverty, low connectivity, etc., including not being attracted by them.

- There is a need to perform science communication actions aimed at various population segments, beyond the emphasis so far provided on children and young people in the educational system. If there is the intention to change the social appropriation of scientific knowledge and technology in the entire population of the regional countries, a greater attention to the adult segments of the public (parents, seniors, unions, businessmen, etc.) should be addressed.

- We recommend Latin American institutions to carry out science communication studies to a greater extent and in a systematic manner their respective socio-cultural environments, i.e. screening needs of the various population segments, researching about the scientific culture and appropriation of S\&T knowledge by social levels, analysing opportunities and threats, etc. This would provide elements and information that would enable them to better target the science communication public. These types of studies, carried out within country or province scopes, preferably because of joint efforts from several institutions linked by the same interest, are strongly suggested.

- We recommend promoting the expansion of academic training and specialized training programs: undergraduate and graduate programs, seminars and workshops, either face-to-face and online initiatives. The latter has the advantage of having relatively low operational costs and wide geographical impact.

- In general, Latin American institutions need to strengthen their management capacities for science communication, including setting up or strengthening appropriate organizational structures, training sufficient and stable specialized teams, implementing management tools, recording activities, evaluating the results of the actions undertaken, improving internal coordination and inter-institutional links and professional external fundraising.

- We especially encourage institutions to develop science communication strategies within mid- to short-term plans and programs, with defined resource allocations, in response to the opportunities and threats that they face in their respective contexts and in the light of their respective strengths and weaknesses.

\section{ACKNOWLEDGMENTS}

The study was sponsored by the UNESCO Regional Bureau of Science for Latin America and the Caribbean and by the Sociedade Brasileira para o Progresso da Ciência. It had the financial support of the, at that time, by the then Departamento de Popularização e Difusão da Ciência e Tecnologia of the Ministério de Ciência, Tecnologia e Inovação (MCTIC), por meio do Conselho Nacional de Desenvolvimento Científico e Tecnológico, CNPq (CNPq 400231/2015-8) from Brazil. 


\section{AUTHOR CONTRIBUTIONS}

All the authors participated equally in the paper, collecting and analysing the data, as well as writing the paper.

\section{REFERENCES}

AMORIM L. 2014. Las mujeres y su espacio en la ciencia en América Latina, SciDev.Net. Available at: http://www. scidev.net/americalatina/genero/scidev-net-en-accion/ las-mujeres-y-su-espacio-en-la-ciencia-en-americalatina. html. Accessed on November 29, 2017.

CAZAUX D. 2010. Historia de la Divulgación Científica en la Argentina. Buenos Aires, Argentina: Editorial Teseo.

FERNÁNDEZ E, BELLO A AND MASSARANI L. 2016. Políticas públicas e instrumentos para el desarrollo de la cultura científica en América Latina Montevideo: LATU; UNESCO; RedPOP.

FOG L. 2004. El periodismo científico en Colombia, un lento despegue. Quark 44: 59-65.

HERRERA S, ESTRADA C, GARCÍA J AND JARAMILLO A. 2006. Diagnóstico de la Divulgación de la ciencia en Jalisco. Guadalajara, Jalisco: COECYTJAL.

MASSARANI L. 2015a. RedPOP: 25 años de popularización de la ciencia en América Latina. Rio de Janeiro: RedPOP, UNESCO, Museu da Vida.

MASSARANI L ET AL. 2017. Aproximaciones a la investigación en divulgación de la ciencia en América Latina a partir de sus artículos académicos. Rio de Janeiro: RedPOP e Casa de Oswaldo Cruz.

MASSARANI L, AGUIRRE C, PEDERSOLI C, REYNOSO E AND LINDEGAARD L. 2015. RedPOP: 25 años de red en comunicación de la ciencia en América Latina. In: Massarani L (Ed), RedPOP: 25 años de popularización de la ciencia en América Latina. 148 a ed., Rio de Janeiro: RedPOP, Unesco, Museu da Vida.

MASSARANI L, AMORIM L, OCA AM AND BAUER M. 2012. Periodismo científico: reflexiones sobre la práctica en América Latina. Chasqui: 120: 73-77.

MASSARANI L, LEON-CASTELLÁ A, AGUIRRE C, REYNOSO E, LINDEGAARD L AND FERNANDEZ E. 2015b. Guía de Centros y Museos de Ciencia de América Latina y el Caribe. Rio de Janeiro: RedPOP-UNESCO y Museu da Vida.

MASSARANI L AND MOREIRA I. 2016. Science communication in Brazil: A historical review and considerations about the current situation. An Acad Bras Cienc 88: 1577-1595.

MASSARANI L, REYNOSO E, MURIELLO S AND CASTILlO A. 2016. Science Communication postgraduate studies in Latin America: A map and some food for thought. JCOM 15: A03.

MOREIRA I AND MASSARANI L. 2002. Aspectos históricos da divulgação científica no Brasil. In: Massarani L, Moreira I and Brito F (Eds), Ciência e Público - caminhos da divulgação científica no Brasil. Rio de Janeiro: Casa da Ciência e Editora da UFRJ, Rio de Janeiro, Brasil, p. 43-64.

ONU - ORGANIZAÇÃO DAS NAÇÕES UNIDAS. 2014. World Urbanization Prospects: The 2014 Revision. ONU Department of Economic and Social Affairs. Population Division. Available at: https://esa.un.org/unpd/wup/ publications/files/wup2014-highlights.pdf. Accessed on November 29, 2017.

ONU - ORGANIZAÇÃO DAS NAÇÕES UNIDAS. 2015. Panorama de la Población Mundial: Revisión 2015. Organización de las Naciones Unidas - División de Población del Departamento de Asuntos Económicos y Sociales de la Secretaría de las Naciones Unidas.

PATIÑO ML. 2013a. La divulgación de la ciencia en México desde distintos campos de acción: Visiones, retos y oportunidades. México, D.F., SOMEDICYT.

PATIÑO ML. 2013b. Análisis de la divulgación de la ciencia y la tecnología en México. Aproximación preliminar a un diagnóstico nacional. Reporte Técnico /Componente 1, Proyecto 208875. México, D.F., SOMEDICYT.

PATIÑO ML, PADILLA J AND MASSARANI L. 2017. Diagnóstico de la Divulgación de la Ciencia en América Latina: Una mirada a la práctica en el campo. $1^{\mathrm{a}}$ ed., Ciudad de México: Fibonacci, RedPOP.

SÁNCHEZ-MORA C, REYNOSO E, SÁNCHEZ-MORA AM AND TAGÜEÑA J. 2015. Public Communication of Science in Mexico: past, present and future of a profession. Public Understanding of Science 24: 38-52. 